Review Article

OPEN ACCESS

\title{
Recent developments for surgical aortic valve replacement: The concept of sutureless valve technology
}

\author{
Thierry Carrel, Lars Englberger, Mario Stalder \\ Clinic for Cardiovascular Surgery, University Hospital Berne, Switzerland \\ Corresponding Author \& Address: \\ Thierry Carrel \\ Chairman, Clinic for Cardiovascular Surgery, University Hospital Berne, $\mathrm{CH}-3006$ Berne, Switzerland; Phone: \\ +41 31632 23 75; Fax: +41 3163244 43; Email: thierry.carrel@insel.ch
}

Published: $12^{\text {th }}$ January, 2013

Accepted: $\quad 12^{\text {th }}$ January, 2013

Received: $5^{\text {th }}$ October, 2012

Open Journal of Cardiology, 2013, 4-1

(C) Carrel et al.; licensee Ross Science Publishers

ROSS Open Access articles will be distributed under the terms of the Creative Commons Attribution License (http://creativecommons.org/licenses/by/3.0), which permits unrestricted use, distribution, and reproduction in any medium, provided that the original work will always be cited properly.

Keywords: Aortic valve stenosis, aortic valve regurgitation, surgical replacement, sutureless valves

\begin{abstract}
Aortic stenosis has become the most frequent type of valvular heart disease in Europe and North America and presents in the large majority of patients as calcified aortic stenosis in adults of advanced age. Surgical aortic valve replacement has been recognized to be the definitive therapy which improves considerably survival for severe aortic stenosis since more than 40 years. In the most recent period, operative mortality of isolated aortic valve replacement for aortic stenosis varies between 1-3\% in low-risk patients younger than 70 years and between 4 and $8 \%$ in selected older adults. Long-term survival following aortic valve replacement is close to that observed in a control population of similar age. Numerous observational studies have consistently demonstrated that corrective surgery in symptomatic patients is invariably followed by a subjective improvement in quality of life and a substantial increase in survival rates.
\end{abstract}

\begin{abstract}
More recently, transcatheter aortic valve implantation (TAVI) has been demonstrated to be feasible in patients with high surgical risk using either a retrograde transfemoral or transsubclavian approach or an antegrade, transapical access. Reported 30-day mortality ranges between 5 and 15\%) and is acceptable when compared to the risk predicted by the logistic EurOSCORE (varying between 20 and 35\%) and the STS Score, although the EuroScore has been shown to markedly overestimate the effective operative risk. One major concern remains the high rate of paravalvular regurgitation which is observed in up to $85 \%$ of the patients and which requires further follow-up and critical evaluation. In addition, long-term durability of these valves with a focus on the effects of crimping remains to be addressed, although 3-5 year results are promising.
\end{abstract}

Sutureless biological valves were designed to simplify and significantly accelerate the surgical replacement of a diseased valve and allow complete excision of the calcified native valve. Until now, there are 3 different sutureless prostheses that have been approved. The $3 f$ Enable valve from ATS-Medtronic received CE market approval in 2010, the Perceval S from Sorin during Q1 of 2011 and the intuity sutureless prosthesis from Edwards in 2012. All these devices aim to facilitate valve surgery and therefore have the potential to decrease the invasivness and to shorten the conventional procedure without compromise in term of excision of the diseased valve. This review summarizes the history and the current knowledge of sutureless valve technology. 


\section{TREATMENT OF VALVULAR AORTIC STENOSIS}

Aortic stenosis has become the most frequent type of valvular heart disease in Europe and North America and presents in the large majority of patients as calcified aortic stenosis in adults of advanced age ( $2-7 \%$ of the population aged more than 65 years) [1-4]. The second most frequent reason for aortic stenosis is of congenital origin in the younger age group, whereas rheumatic aortic stenosis has become rare but still present in developing countries.

Echocardiography has become the principal diagnostic examination method and easily allows to confirm the presence of valvular aortic stenosis, to assess the degree of valve calcification, the function, the size and the wall tickness of the left ventricle. A valve area $<1.0$ $\mathrm{cm} 2$ is considered as severe aortic stenosis, but indexing this value to body surface area, with a cut-off value of $<0.6 \mathrm{~cm} 2 / \mathrm{m} 2$ body surface area is helpful, in particular in patients with unusually small or large body surface. Computed tomography and magnetic resonance imaging allow complete assessment of the thoracic aorta (root, ascending, arch and descending segments). In patients over age of 40 years, cardiac catheterism allows to assess invasively transvalvular pressure gradients and hemodynamic conditions whereas coronary angiography gives important informations about the coronary arteries. Valvular aortic stenosis is a chronic progressive disease. The patients may remain asymptomatic during a long time and sudden cardiac death may happen in symptomatic patients [ㅁ-ㄱ] Early valve replacement should be strongly recommended in all symptomatic patients with severe aortic stenosis who are considered to be candidates for surgery. As long as the mean gradient remains above $>40 \mathrm{mmHg}$, there is virtually no lower EF limit for surgery.

Surgical aortic valve replacement has been recognized to be the definitive therapy (which improves considerably survival) for severe aortic stenosis since more than 40 years. In the most recent period, operative mortality of isolated aortic valve replacement for aortic stenosis varies between $1-3 \%$ in low-risk patients younger than 70 years and between 4 and $8 \%$ in selected older adults $[\underline{2}, \underline{8}, \underline{9}]$. The following factors have been recognized to increase significantly the risk of surgery: older age, associated comorbidities, female gender, higher NYHA functional class, emergency operation, left-ventricular dysfunction, pulmonary hypertension, coexisting coronary disease, and redo-intervention. Long-term survival following aortic valve replacement is close to that observed in a control population of similar age. Numerous observational studies have consistently demonstrated that corrective surgery in symptomatic patients is invariably followed by a subjective improvement in quality of life and a substantial increase in survival rates. In addition, AVR may also provide survival benefit for selected asymptomatic patients, when compared to conservative management [10-16]. The 2012 update of the ESC/EACTS Guidelines for the management of patients with valvular heart disease also states that aortic valve replacement may be considered for asymptomatic patients with severe aortic stenosis and abnormal response to exercise [1]].

Several considerations must be addressed whenever surgical correction of aortic stenosis is warranted, such as the choice of a mechanical valve versus the use of a bioprosthetic valve, including stented and stentless valves, aortic homografts, cadaveric recovered autografts. While mechanical valves are more durable in general, bioprosthetic valves and do not require lifelong anticoagulation. Stentless bioprosthetic valves were first introduced in the 1990's and are reported to have superior hemodynamic properties comparing to stented valves due to lower pressure gradients and reduced turbulence in the aortic sinuses. This ensures superior coronary circulation during diastole [1] ].

More recently, transcatheter aortic valve implantation (TAVI) has been demonstrated to be feasible in patients with high surgical risk using either a retrograde transfemoral transsubclavian or direct aortic approach or an antegrade, transapical access [19-26]. Reported 30 -day mortality ranges between 5 and $15 \%$ and is acceptable when compared to the risk predicted by the logistic EuroSCORE (varying between 20 and 35\%) and the STS Score, although the EuroScore has been shown to markedly overestimate the effective operative 
risk [27]. One major concern remains the high rate of paravalvular regurgitation which is observed in up to $85 \%$ of the patients and which requires further follow-up and critical evaluation. In addition, long-term durability of these valves with a focus on the effects of crimping remains to be addressed, although 3-5 year results are promising [26].

In addition, the occurence of paravalvular regurgitation in TAVI has been shown to be predictive for mid-term survival [28].

Management of asymptomatic severe aortic stenosis remains a matter of controversy [29-31]. The decision to operate on asymptomatic patients requires careful weighing of benefits against risks. Watchful waiting appears particularly safe and the benefit of early surgery seems highly unlikely in patients with normal exercise tests and normal/low natriuretic peptide levels. Early elective surgery should only be considered in selected patients at low operative risk with one or more of the following situations: 1) Depressed LV function not due to other causes, 2) Combination of a markedly calcified valve with a rapid increase in peak transvalvular velocity of $\geq 0.3 \mathrm{~m} / \mathrm{s}$ per year, 3) Abnormal exercise test, particularly one with symptom development or fall of blood pressure below baseline, 4) Severly elevated natriuretic peptide levels confirmed by repeated measurements without other explanations, 5) Excessive LV hypertrophy without history of hypertension and 6) Very severe AS defined by a peak velocity $>5-5.5 \mathrm{~m} / \mathrm{s}$ and 7 ) Increase of mean pressure gradient with exercise by $>20 \mathrm{mmHg}$ [32].

\section{CHOICE OF THE PROSTHETIC VALVE WITH SPECIAL EMPHASISIS ON SUTURELESS VALVE TECHNOLOGY}

In 1954, Hufnagel and colleagues described 23 patients with aortic insufficiency who had been treated during the previous 2 years by rapid insertion of an acrylic ball valve into the descending aorta [33]. Since the valve prevented regurgitant flow only from the low part of the body, cardiac work was only partially decreased. In addition, embolization and thrombosis of the valve appeared quite often. In September 1960, Starr performed the first successful mitral valve replacement using a caged ball valve [34].

At that time, pioneer surgeons recognized that the ideal valve shoud be chemically inert, compatible with human tissues, atraumatic to blood cells and nonthrombogenic. In addition they looked for a prosthesis to be implanted securely in a physiologic position. With further development in mechanical prostheses (tilting disk, bileaflet valve), and major advances in the field of biological prostheses, valve replacement surgery improved considerably the natural history of patients with mitral and aortic stenosis and regurgitation [35]. Despite major advances in technologies, there are still no perfect valve substitutes. Whether mechanical or biological, all prosthetic valves have some advantages but also some inconvenients for the patients. The most recent bileaflet and tilting-disk mechanical valves have the theoretical advantage of longterm absence of any structural degeneration but they require lifelong anticoagulation. In contrast, all tissue valves (including homografts, pulmonary autografts, as well as porcine and pericardial bovine or equine bioprostheses) do not require long-term anticoagulation, but they are all subject to structural valve deterioration over time. Biological valves can be further subdivided into stented and stentless. The design of the stentless valves was intended to provide a better effective valve area. More favourable haemodynamics have been reported, but no improvement in long-term durability has been demonstrated so far. Sutureless valves are an incoming technology that allows quick placement of a bioprosthesis without a sewing cuff. This technology will be presented hereafter with more details.

In practice, the choice is between a mechanical prosthesis and a bioprosthesis in the majority of patients. The heterogeneity of valvular heart diseases and the variability of outcome of complex procedures make the design and the execution of prospective randomised trials difficult. Two historical randomized trials comparing older models of mechanical and bioprosthetic valves found no significant difference in rates of valve thrombosis and thromboembolism, in accordance with numerous individual valve series. Long-term survival was very similar [ $\underline{36}$, 37]. A more recent trial randomised 310 patients 
aged 55 to 70 to mechanical or biological prosthesis [38]. No differences were found in survival, thromboembolism, and bleeding rates but - as expected - a higher rate of valve failure and reoperation following implantation of bioprostheses. The choice between a mechanical valve and a bioprosthesis in adult patients is mainly determined by assessing the risk of anticoagulant-related bleeding and thromboembolism with a mechanical valve versus the risk of valve degeneration with a bioprosthesis and by considering the patient's goals, values and preferences for life and healthcare [39-42].

Rather than setting arbitrary age limits, prosthesis choice is usually considered on an individual basis and discussed in detail with the patient, taking into account the following: bioprostheses should be considered in patients whose life expectancy is lower than the presumed durability of the bioprosthesis, particularly if comorbidities will necessitate other surgical procedures in the future, and in those with increased bleeding risk. Although structural valve degeneration is accelerated in chronic renal failure, poor long-term survival with either type of prosthesis, and an increased risk of complications with mechanical valves, may favour the choice of a bioprosthesis in this situation [43]. Quality of life issues and informed patient preferences must also be taken into account. Inconvenience of oral anticoagulation can be minimised by self-management of anticoagulation [44]. Although bioprosthetic recipients can avoid long-term anticoagulation, they face the possibility of deterioration of their clinical condition due to degeneration of the bioprosthesis and the prospect of reoperation if they live long enough. During mid-term followup certain patients receiving a bioprosthetic valve may develop another condition requiring oral anticoagulation (atrial fibrillation, stroke, peripheral arterial disease and other).

\section{CURRENT EXPERIENCE WITH SUTURELESS VALVES}

The concept of sutureless valve was already tested in the early sixties [4ㄷ], with the idea to facilitate implantation and shorten ischemic and perfusion times. However, the concept was abandoned due to multiple complications, such as paravalvular leakage and valve-related thromboembolic events. Recently, sutureless aortic valve implantation has received increasing interest, due to the rapid development of transcatheter valve technology. Shortening the time required for aortic valve replacement may help to reduce the morbidity and mortality, especially in patients who require complex multivalve or combined valve and coronary procedures.

Sutureless biological valves were designed to simplify and significantly accelerate the surgical replacement of a diseased valve and require first complete excision of the calcified native valve. Until now, there are 3 different sutureless prostheses that have been approved. The $3 f$ Enable valve from ATS-Medtronic received CE market approval in 2010, the Perceval S from Sorin during Q1 of 2011 and the Intuity sutureless prosthesis from Edwards most recently in 2012 entered pilot clinical investigation. There are to date more than 40 patents with respect to sutureless valve technologies.

\section{THE ENABLE VALVE FROM ATS- MEDTRONIC}

The Enable valve combines the characteristics of the $3 f$ stentless valve to a nitinol stent which unfolds at normal temperature. To better understand the concept of the 3f-Enable valve, a short summary on the original stentless valve and the clinical results will be given first.

\section{THE 3F STENTLESS VALVE FROM ATS}

The ATS-Medtronic $3 f^{\circledR} \quad$ Aortic Bioprosthesis Model 1000 is a stentless bioprosthesis with excellent mechanical properties and performance characteristics. It was designed with the aim to mimic the physiological function of the native aortic valve as closely as possible. It is known from human embryonic studies that the primary structure of the aortic valve is tubular and adopts its shape to the hemodynamic forces during the cardiac cycle when fully developed, thus ensuring unidirectional blood flow. The ATS $3 f$ valve was designed with these anatomical functional properties in mind ( $3 f$ - form follows function). 


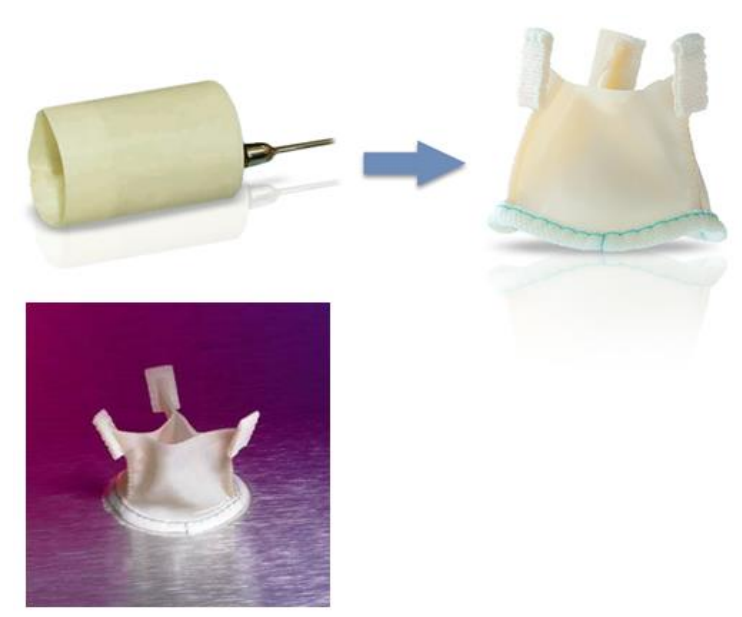

Figure 1. Tubular structure of the stentless 3-f aortic tissue valve

The valve structure is assembled together from three equal sections of glutaraldehydefixed equine pericardial tissue. Glutaraldehyde is used to preserve the collagen matrix of the pericardium and to reduce its immunogenic and thrombogenic potentials while preserving its strength and flexibility. A thin sewing ring is added to the proximal orifice of the bioprosthesis to be attached to the aortic root orifice after dissection of the native, diseased valve. The distal portion of the valve has three commissural tabs that are attached to the aortic wall using locking sutures. The above design allows the $3 \mathrm{f}$ valve to closely mimic the function of the native aortic valves.

The anatomic design of the valve is emphasized by the fact that it appears very similar than the native aortic valve both visually and in functionality on echocardiography. In addition, salient features of this "cuspal" replacement include: 1) Absence of animal arterial wall (seen with porcine bioprostheses that may fuse to the native aortic wall by calcification within 5 years of implantation); 2) Preservation of the aorto-ventricular junction and the sino-tubular junction continuity thus retaining the function of the sinuses of Valsalva; 3) Restoration of native valve stress distribution; 4) Improved coronary artery blood flow during diastole minimizing myocardial ischemia; 5) Restored physiological blood flow without areas of stagnation.

The Medtronic-ATS $3 \mathrm{f}^{\circledR} \quad$ Aortic Bioprosthesis Model 1000 has been tested extensively per the US Food and Drug Administration (FDA) and International
Standards Organization (ISO) guidelines in the pre-clinical stage. Results of the in vitro and in vivo studies were favorable compared to controls of commercially available stentless and stented valves. Subsequently, a clinical investigation protocol was developed with the goal to enroll patients presenting with severe aortic stenosis or combined lesions of aortic stenosis and insufficiency. It is the objective of the following section to present the mid-term results of a subset of investigational sites participating in a multicenter, prospective clinical study with the $3 f^{\circledR}$ Aortic Bioprosthesis Model 1000 [46].

\section{CLINICAL EXPERIENCE WITH THE 3F- STENTLESS IN THE PROSPECTIVE MULTICENTRIC STUDY}

One hundred and sixty five patients (109 males, 56 females, average age: $67.8 \pm 12.7$ years) were implanted with the $3 \mathrm{f}$ valve as part of a prospective, international, multicenter, non randomized study at 4 investigational sites. Valve replacement surgeries were performed between 2001 and 2004. Patients requiring isolated aortic valve replacement with or without concomitant procedures, except for mitral, pulmonary or tricuspid valve replacement, and with average or better operative risk were eligible to participate. Exclusion criteria included age below 20 years, life expectancy of 12 months or less, congenital bicuspid aortic anatomy and previously implanted prosthetic heart valve that is not being replaced by the study valve. Subjects not agreeable to return to the implant centre for the required number of follow up visits and those who participated in concomitant research studies of investigational products were also excluded.

The indication for the aortic valve replacement was degenerative (69.1\%), rheumatic $(27.7 \%)$, congenital $(7.4 \%)$, and previous endocarditis-related $(0.6 \%)$ aortic valve pathology. Notably, $4.8 \%$ of patients had more than one indication for the surgery, such as degenerative disease due to congenital aortic valve anomaly. Transesophageal echocardiography was performed intraoperatively to verify correct valve positioning and to assess for paravalvular leak. Patients were followed prospectively for 
$3.07 \pm 1.50$ years (506.74 patient years) at regularly scheduled visits. In addition to routine physical examination and chemistry panel, transthoracic echocardiogram was performed at hospital discharge, at 3 and 6 months postsurgery and annually thereafter. TEE and TTE images were forwarded to an independent echocardiographic core laboratory for data analysis. All adverse events were recorded and

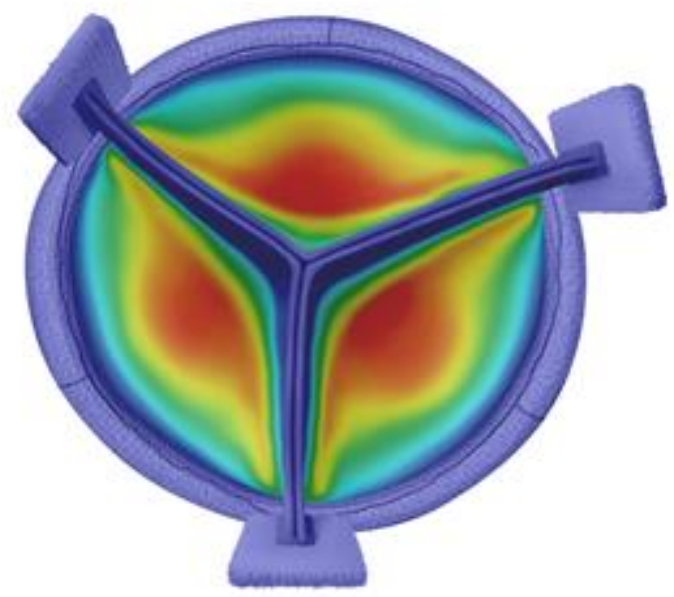

analyzed in accordance with regulatory requirements. Early adverse events were defined as complications occurring within the first 30 days post-implantation. All subsequent complications were categorized as late adverse events. The study was conducted according to the applicable local and international regulatory requirements and was approved by the local ethics committee at each institution.

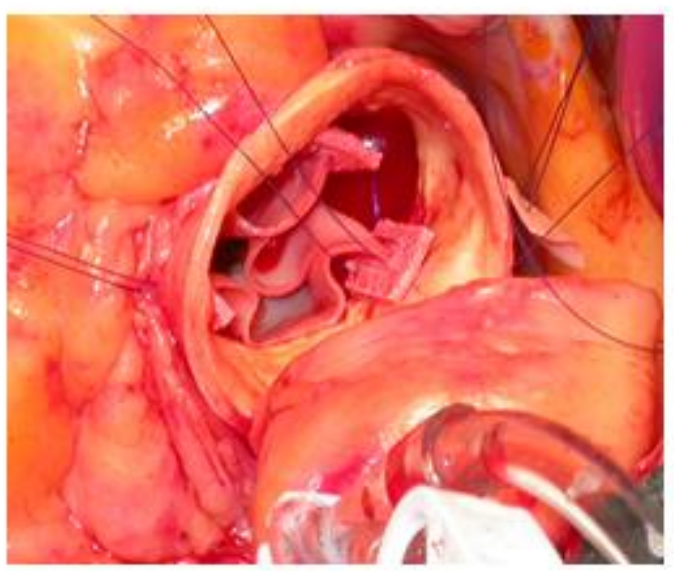

Figure 2. (left) Native valve form and function is reproduced resulting in minimal stresses at the commissures and more evenly distributed stresses throughout the leaflet. (right) 3-f tissue valve in the native aortic root: note the large coaptation line.

Prosthetic valves with the following size distribution were implanted: $21 \mathrm{~mm}(7.4 \%)$, $23 \mathrm{~mm}$ (28.4\%), $25 \mathrm{~mm}$ (25.9\%), 27mm (19.8\%), and $29 \mathrm{~mm}(18.5 \%)$. Five patients $(3.0 \%)$ died within the immediate perioperative period; 1 due to valve-related while 4 due to non valve related causes. The cause of death was fulminant sepsis in 2 patients; cerebral thromboembolism in 1 subject, acute myocardial infarction in 1 patient and acute systolic heart failure with concomitant multiorgan failure in 1 subject. Early non-fatal complications were limited to ischemic cerebrovascular events in 3 patients (1.8\%). As demonstrated on Figure 1, valve-related mortality was very low during the study period (cumulative freedom from valverelated mortality is $98.5 \%$ after five years of follow-up).

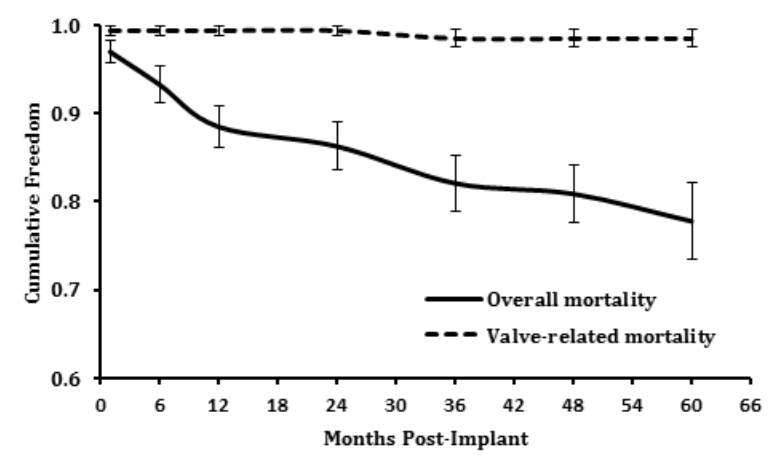

Figure 3. Cumulative freedom of valve-related and overall mortality

A late adverse event was recorded in 23 patients $(4.5 \%$ /patient year) during the five years follow-up period. 13 participants $(2.57 \%$ /patient year) suffered a thromboembolic event: 1 pulmonary embolism and 12 cerebrovascular events were reported, 5 of these were consistent with transient neurological deficit. Endocarditis was documented in 4 patients $(0.79 \%$ /patient year), all of which resulted in valve explantation. In addition, valve explantation was necessary in 2 cases $(0.4 \%$ /patient year) due to echocardiographic 
evidence of paravalvular leak. No structural prosthetic deterioration or valve thrombosis occurred during the five years follow up.

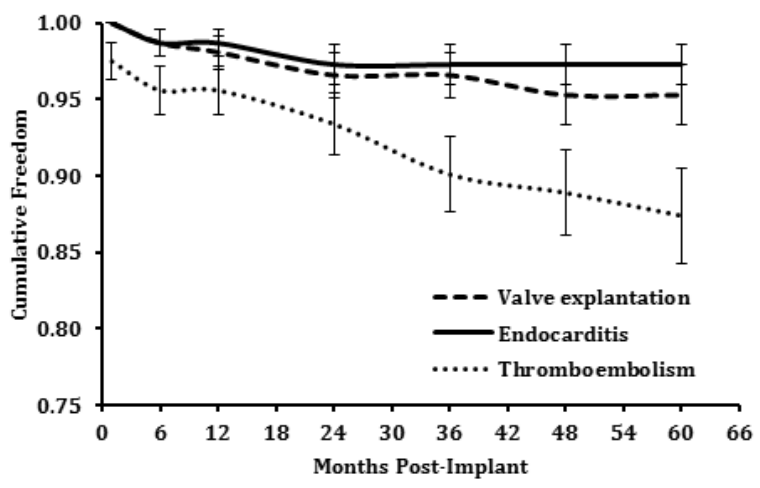

Figure 4. Cumulative freedom from adverse events.

Hemodynamic parameters, as assessed with TTE at the time of hospital discharge, at 12 and 36 months post-surgery are listed in Ta. Notably, the mean aortic gradient was measured at $12.1 \mathrm{mmHg}$ at discharge and at $9.4 \mathrm{mmHg}$ at 36 months with the difference reaching statistical significance. In accordance, peak aortic gradient decreased from 21.8 to $17.5 \mathrm{mmHg}$ by the third postoperative year with the reduction again being statistically significant. The effective orifice area (1.9 \pm 0.7 at discharge and $2.0 \pm 0.7$ $\mathrm{cm} 2$ at 3 years), indexed effective orifice area $(1.0 \pm 0.4$ at discharge and $1.0 \pm 0.3 \mathrm{~cm} 2 / \mathrm{m} 2$ at 3 years), cardiac output (5.3 \pm 1.5 at discharge and $5.1 \pm 1.3 \mathrm{~L} / \mathrm{min}$ at 3 years) and cardiac index ( 2.8 \pm 0.8 at discharge and $2.7 \pm 0.6 \mathrm{~L} / \mathrm{min} / \mathrm{m} 2$ at 3 years) were sustained during the follow-up period (Table 1 below).

Table 1. Postoperative haemodynamic parameters

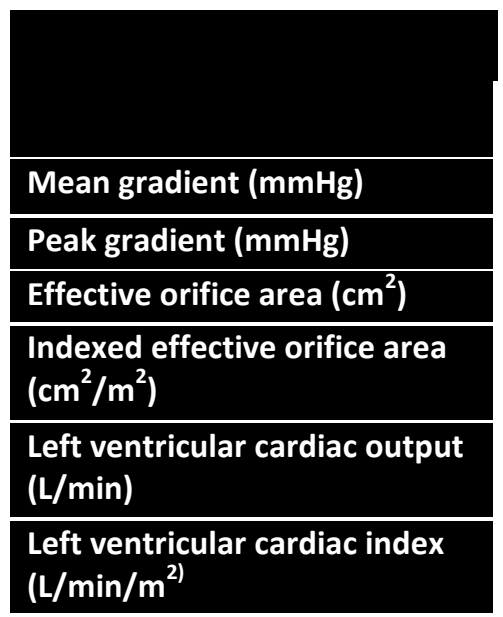

\begin{tabular}{|c|c|c|c|c|c|c|}
\hline Discharge & $\mathbf{n}$ & \multicolumn{4}{|c|}{ Post implantation } & p* \\
\cline { 3 - 7 } & & 1 year & $\mathbf{n}$ & 3 years & $\mathbf{n}$ & \\
\hline $12.1 \pm 6.5$ & 148 & $11.2 \pm 5.1$ & 127 & $9.4 \pm 4.0$ & 75 & 0.0045 \\
\hline $21.8 \pm 11.3$ & 148 & $19.7 \pm 8.5$ & 127 & $17.5 \pm 7.2$ & 75 & 0.0251 \\
\hline $1.9 \pm 0.7$ & 106 & $1.9 \pm 0.7$ & 100 & $2.0 \pm 0.7$ & 55 & 0.6089 \\
\hline $1.0 \pm 0.4$ & 100 & $1.0 \pm 0.3$ & 90 & $1.0 \pm 0.3$ & 55 & 0.7640 \\
\hline $5.3 \pm 1.5$ & 112 & $5.1 \pm 1.4$ & 103 & $5.1 \pm 1.3$ & 57 & 0.1279 \\
\hline $2.8 \pm 0.8$ & 107 & $2.7 \pm 0.7$ & 94 & $2.7 \pm 0.6$ & 57 & 0.1546 \\
\hline
\end{tabular}

The valve proved to be versatile and has shown superior intraoperative handling characteristics. Despite reports indicating that stentless aortic valves generally require a more complex surgical approach than stented valves, they indeed carry a similar operative risk. As an added advantage for the surgeons, this unique valve requires only one circumferential suture line at the inflow side thereby saving operative time and allowing less complicated implantation procedure [47-49]. As such, no lengthy learning curve or major inter individual differences were observed among surgeons at different sites with regards to aortic cross-clamp times and procedural complications. In addition to the good hemodynamic profile, the valve has demonstrated a safe clinical profile in this patient cohort. Early fatal complications were limited to $3 \%$ including one valve-related death $(0.6 \%)$ and 4 non valve related fatalities (2.4\%). Non-fatal complications were documented in $1.8 \%$ of patients. Late adverse events were recorded in $4.5 \%$ /patient-year during the follow-up period, including thromboembolic events, endocarditis and paravalvular leak. No structural prosthetic deterioration or valve thrombosis occurred during the entire study period. Cumulative freedom from valve-related mortality was $98.5 \%$ after five years of followup. Overall, the adverse event rate with the ATS $3 f^{\circledast}$ Aortic Bioprosthesis was comparable to those observed with other commercially available stentless aortic valves. However, no structural valve deterioration was detected in the present study. Indeed, in vitro tests indicated the superior durability of the valve 
when compared to test devices, most likely due to the improved leaflet stresses. Continued clinical follow up continues to document the long-term performance, durability and safety profile of this unique bioprosthesis.

\section{ENABLE I DEVICE DESCRIPTION}

The $3 f$ Enable $^{\circledR}$ Aortic Bioprosthesis Model 6000, was developed for aortic valve replacement. Like in the $3 f$ tissue valve, the valve leaflets are designed to simulate the tubular nature of valvular development in utero. The device consists of the following: a $3 f$ Aortic Bioprosthesis Model 1000 assembled from three equal sections of equine pericardial material that have been cross-linked with formulations of low concentration glutaraldehyde under specific parameters of time, $\mathrm{pH}$ and temperature. This fixation process preserves the collagen architecture of the pericardial material, minimizes the immunogenic potential of the xenogeneic tissue, and preserves flexibility and strength. The valve has been introduced in a selfexpanding Nitinol frame. A polyester fabric covers the inflow flange/skirt (igure 5).

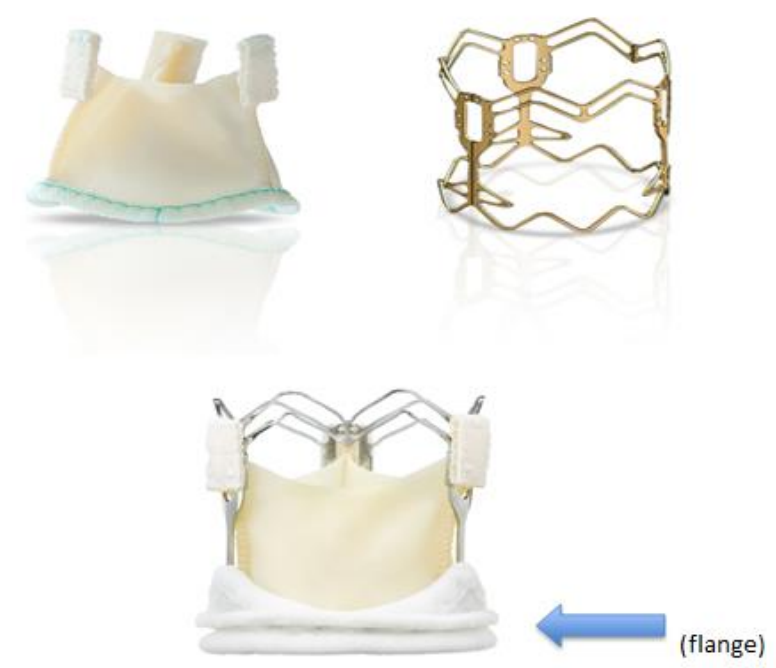

Figure 5. $3 \mathrm{f}$ stentless valve Model 1000 (top left) and Nitinol Frame (top right)

The $3 f$ Enable $^{\circledR}$ Aortic Bioprosthesis Model 6000 (bottom)

The design concept of the Model 6000 valve are three equal equine pericardial leaflets that are assembled into a tubular structure, and result in three equispaced commissural tabs of special design just like the Model 1000 . These tabs are reinforced with equal sections of polyester material and are fixed into specially designed commissural tab attachment eyelets in the superior aspect of the NiTiNOL frame. The self-expanding NiTiNOL frame contributes partly to the fixation of the device, in the deployed location, by virtue of outwardly emitted, radial forces inherent in the NiTiNOL material (chronic outward force). This allows for the use of the only one guiding stitch to correct placement of the valve to the annulus. Further contributions to fixation into the aortic root are provided by the polyester fabric covering on the inflow aspect of the device. The polyester flange has been incorporated at the inflow aspect to minimize the potential of perivalvular leaks and migration, and apposes well to the aortic annulus without blocking the coronary ostia. The Model 6000 has a polyacetal homopolymer folding sleeve that is attached to the valve and is used in conjunction with an accessory inserter system to aid in folding and insertion of the valve.

The Model 6000 bioprosthesis is supplied in diameters of: $19 \mathrm{~mm}, 21 \mathrm{~mm}, 23 \mathrm{~mm}, 25 \mathrm{~mm}$, $27 \mathrm{~mm}$ and $29 \mathrm{~mm}$. These sizes correspond to the orifice created by removal of the diseased valve from the aortic root and can be measured with the obturators supplied. The picture of the Model 6000, Enable valve, identifies the "flange" of the valve. The inflow of the valve has a portion that is covered with polyester material. We refer to this section of the valve as the "flange". The Enable valve is a sutureless valve, thus, there is no sewing ring attached to the valve. Inadvertently, people have referred to this section of the valve as the flange, inflow flange, skirt, or even "sewing ring"; however, these are the same part of the valve.

The scalloped polyester flange conforms to the aortic annulus of the patient. The scalloped flange is $2 \mathrm{~mm}$ in thickness and should be positioned approximately $1 \mathrm{~mm}$ above or on the aortic annulus (i.e., supra-annularly). The pliable nitinol-stent allows for crimping the valve at low temperatures at about $5^{\circ} \mathrm{C}$. The stent regains its original shape at room temperature due to the memory effect of the nitinol.

\section{OWN EXPERIENCE}

Outcome analysis of a consecutive series of 28 patients who underwent aortic valve

Page $\mathbf{8}$ of $\mathbf{2 1}$

(Page number not for citation purposes) 
replacement (AVR) for aortic stenosis with the ATS 3f-Enable ${ }^{\mathrm{TM}}$ during a 18 months-period. The study was approved by the institutional review board of Berne University Hospital and all patients gave written informed consent. Mean age of the patients was $75.7 \pm 6.6$ years, 18 were

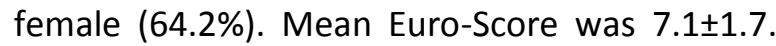
The majority of implanted valves was $23 \mathrm{~mm}$ in diameter (range: $19-27 \mathrm{~mm}$ ). Mean aortic crossclamping time was 39 \pm 15 min (range: $29-103$ min) and mean cardiopulmonary bypass time was $58 \pm 20$ min (range: 41-127). No intraoperative complications, such as valve migration, coronary ostia obstruction, mitral regurgitation or injury to the ascending aorta occurred in this series.

Three patients were found to have paravalvular leakage because of insufficient valve expansion; in 2 cases the valve implanted was too large and the Nitinol-stent could not fully expand. In these cases, the next smaller valve was implanted without difficulty. In one patient, the surgeon decided to proceed with a stented bioprosthesis.

Mean length of hospital stay was 11 days [7-22]. 30 day-mortality rate was 3.5\%. Mean and peak intraoperative transvalvular pressure gradients were respectively $6.1 \pm 2.6 \mathrm{mmHg}$ and $18 \pm 5 \mathrm{mmHg}$. Trivial and mild paravalvular leak was observed in one patient each. One patient underwent redo-AVR 4 months after initial surgery due to severe valve-unrelated paravalvular leakage. 5 patients $(18.5 \%)$ required permanent pacemaker. Postoperative anticoagulation consisted in acetylsalicylic acid $100 \mathrm{mg}$. Oral anticoagulation was administred only in presence of any additional risk factor (atrial fibrillation, ejection fraction below $30 \%$ ). Follow-up consisted of clinical examinations as well as intra- and postoperative echocardiography (at discharge, 6 and 12 months).

Main exclusion criteria were: patients with previous cardiac surgery, dilated $(>4 \mathrm{~cm})$ and severly calcified ascending aorta and aortic root, as well as active endocarditis. Combined AVR and myocardial revascularization was not an exclusion criterium. One patient developed significant leakage after 3 months. One month later, the Enable valve was replaced with a biological stented valve. Explantation of the valve was very easy; the valve was intact (Figure 6). The reason for leakage was valve-unrelated. A localized detachment of the anterior mitral valve leaflet was found to be related to deep decalcification of the native aortic annulus. Discordance between the sinotubular ridge and diameter of the aortic annulus is not of concern for this type of valve, since fixation occurs only at the level of the annulus. No patient was lost from follow-up and 1-year survival was $86.2 \%$. The procedure was fast but not as short as expected. This experience has lead to major modifications of the design, which will facilitate and accelerate implantation.

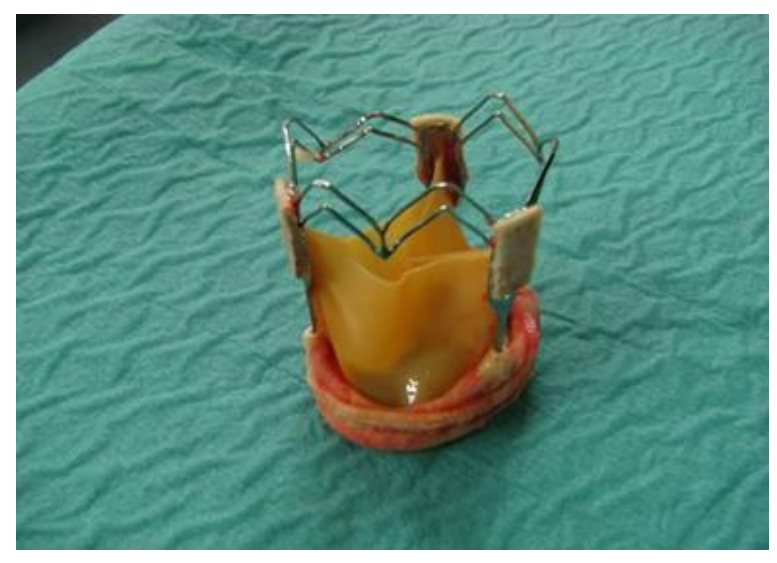

Figure 6. Explanted Enable valve because of paravalvular leak: no structural changes of the valve were noted.

\section{IMPLANTATION TECHNIQUE}

Surgery is performed under full sternotomy or mini-sternotomy. Standard cardiopulmonary bypass (CPB) was established by cannulation of the ascending aorta and the right atrium. Myocardial protection was achieved by $100 \mathrm{ml}$ antegrade crystalloid singleshot cardioplegia (Cardioplexol ${ }^{\circledR}$, Bichsel Laboratory, Interlaken, Switzerland). Transverse aortotomy was performed approximatively $2 \mathrm{~cm}$ above the commissures. The valve was excised and the annulus decalcified as for conventional AVR.

Sizing of the prosthesis is a crucial step since neither over- nor undersizing is recommendable, because the sizes of the device are really true sizes and it is not possible to expand an oversized Enable valve in a smaller annulus. Following usual rinsing ( 3 times 30 sec.), the valve is merged in ice-sludge to allow 
the folding (Figure 7) and insertion of the stented valve into the applicator (Figure 8). If necessary a guiding stitch is placed at the level of the lowest point of the native annulus in one of the intracommissural trigones (preferably at the left - non-coronary commissure), to avoid rotation or to deep insertion of the valve. The stitch is passed through the suture ring of the valve and the prosthesis is pushed out of the applicator. Expansion of the nitinol stented valve is performed under constant observation using warm saline solution. The tabs are not sutured to the aortic wall but attached to the stent; they come in contact with the aortic wall after expansion of the valve (Figure 9). Inspection of the coronary ostia is very easy due to the intraannular position of the valve. The aortotomy is closed with a running suture and the operation terminated in the usual way. Position and function of the valve were assessed by intraoperative TEE immediately after weaning from CPB.

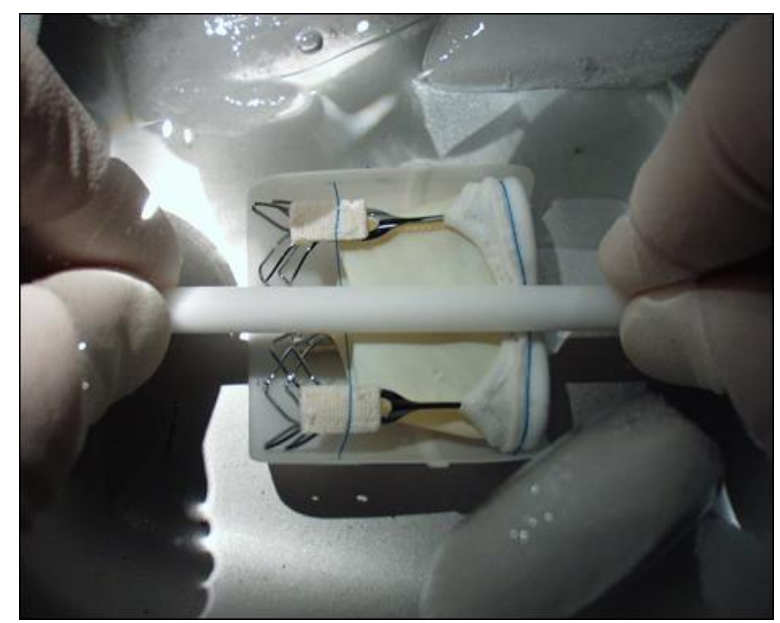

Figure 7. Folding of the valve in iced solution

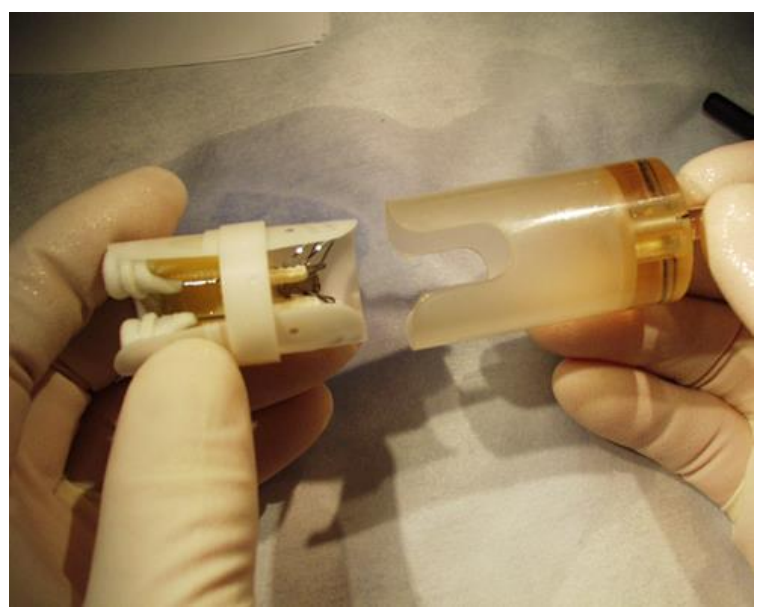

Figure 8. Introduction of the folded valve in the delivery device

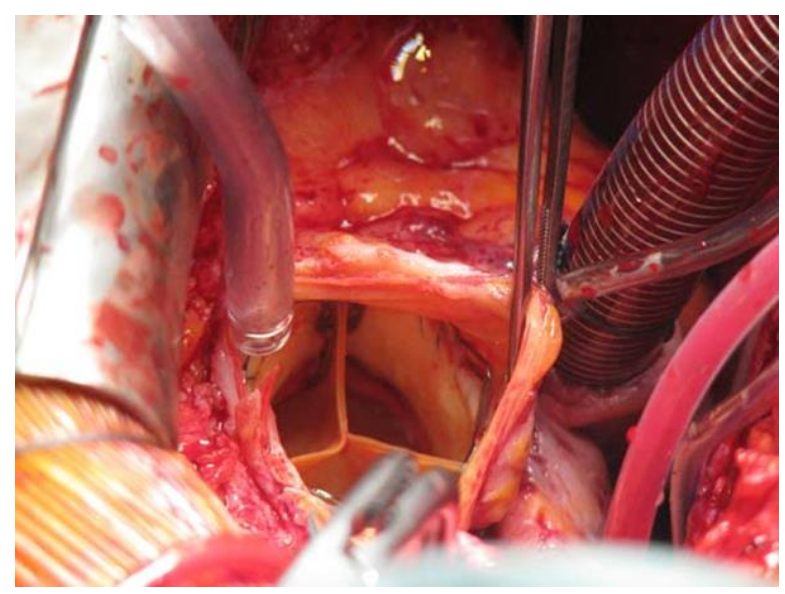

Figure 9. Intraoperative situs following deployment of the valve, immediately before closure of aortotomy

\section{THE PERCEVAL S SUTURELESS VALVE}

Perceval $\mathrm{S}$ is a prosthetic valve comprising a bovine pericardium tissue valve attached to a self-expandable anchoring device, which has the dual role of supporting the valve and providing fixation to the implantation site (Figure 10). The anchoring device design is characterized by two ring segments (outflow and inflow ring), three commissural elements supporting the valve, and three pairs of sinusoidal elements providing fixation in the sinuses of Valsalva. The material used for the anchoring device is an equiatomic alloy of Nickel and Titanium called Nitinol, able to bear large recoverable deformation (approximately 8 to 10 times that of steel), regaining its initial shape when stress is removed (deformation-driven Superelastic effect). Therefore, the Perceval $\mathrm{S}$ prosthesis can be compressed for the implantation and is able to reach its final diameter when released.
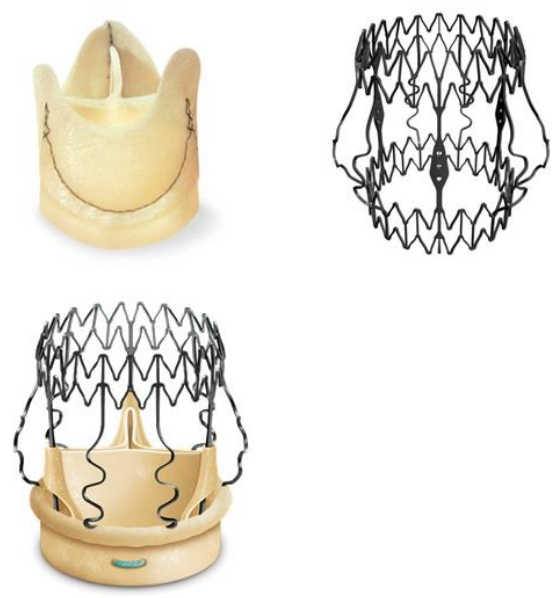

Figure 10. Stentless Solo tissue valve (top left). Anchoring device (top right) and the Perceval $S$ sutureless valve (bottom). 
The anchoring device is coated with CarbofilmTM, a thin turbostratic carbon film which improves material haemo- and biocompatibility. The tissue valve is manufactured as any other Sorin (Saluggia, Italy) bovine pericardial valve: the clinically proven double-sheet pericardium valve design is completed by a pericardial sealing collar encouraging adaptation to the aortic annulus and preventing paravalvular leakage [50]. In correspondence to each valve sinus a button hole is provided on the inflow ring, through which temporary guide threads are passed to aid prosthesis positioning. The bovine pericardial tissue used for Perceval $S$ is stabilised using a clinically proven glutaraldehyde fixation process, followed by a proprietary aldehyde residues neutralization treatment which allows to avoid rinsing.

The prosthetic implant is supported by dedicated tools: crimping system, manometer and dilatation balloon (Figure 11). In fact, prior to implantation the prosthesis diameter is reduced to a suitable size, using the Perceval $\mathrm{S}$ collapsing tool, and then loaded on the Perceval $S$ holder (Figure 12). After in situ positioning the valve is released in two steps: first the inflow ring is released at the annulus level and then, when proper positioning is verified, the complete prosthesis release is achieved. Following implant Perceval $S$ post-dilation balloon catheter is inflated inside the prosthesis at the inflow level to improve apposition by modeling the inflow ring on the annulus. Perceval $\mathrm{S}$ bendable dual ended sizers assist the physician in choosing the proper prosthesis size: their design allows visibility of the annulus, fits also with complex anatomy and helps obtaining an ideal positioning with respect to the commissures.
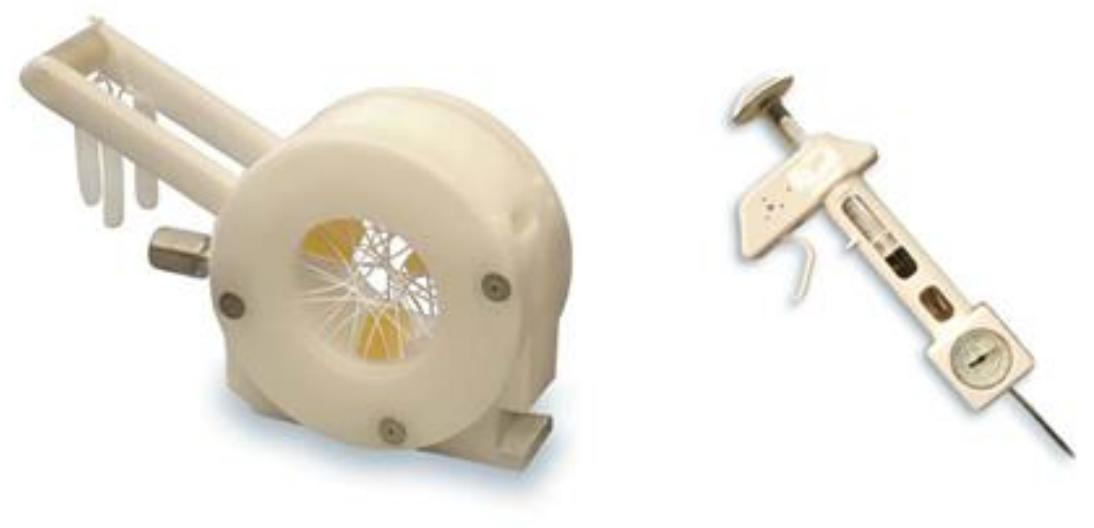

Figure 11. Crimping instrument and balloon catheter for the deployment perceval valve.

In vitro accelerated fatigue tests were performed under normal and hypertensive conditions, demonstrating that the whole prosthesis remains functional up to 900 Million cycles (more than 20 year of equivalent life). These outstanding results exceed the minimal ISO and FDA requirements and suggest a wide safety margin of the Perceval $\mathrm{S}$ prosthesis.

At the present time, the Perceval $S$ prosthesis has been investigated in three clinical studies:
1. the "PERCEVAL TRIAL - Perceval S valve pilot trial - V10601",

2. the "PERCEVAL Pivotal Trial - V10801" and

3. the "CAVALIER - Perceval $S$ valve clinical trial for extended CE mark - TPS001".

The pilot trial was aimed at demonstrating the 30-days safety of the Perceval S valve in 30 high risk patients requiring aortic valve replacement due to stenosis or stenoinsufficiency. This prospective and nonrandomised study was conducted at 3 European 
Investigational Centres between April 2007 and February 2008. The valve size range comprised 21 and 23 sizes and the target patients were high risk population for surgical procedure (e.g. subjects older than 75 years, with NYHA class III and IV, Logistic EuroSCORE $>5 \%$, without aortic dilatation). The valve was implanted following sternotomy, extracorporeal circulation (ECC), aortic cross-clamping, cardioplegic arrest, and removal of the native valve. Implantation suturing was not required. Optimal annular sealing was obtained with brief low-pressure balloon dilation. If coronary bypass was indicated, a distal anastomosis was performed first. Between April 2007 and February 2008, 30 patients (mean age: $81+/-4$ years) underwent aortic valve replacement. With this device in our institution the prevalence of pure aortic stenosis was $76.7 \%$, and that of mixed lesion $23.3 \%$. The mean logistic EuroSCORE was $13.18 \%$, and the NYHA class was III and IV in $93.3 \%$ and $6.7 \%$ of patients, respectively. The implanted valve size was 21 and $23 \mathrm{~mm}$ in $37 \%$ and $63 \%$ of patients, respectively, and 14 (46.7\%) underwent coronary artery bypass grafting (11 internal mammary arteries, nine vein grafts). The mean aortic cross-clamp and ECC times were $34+/-15$ min and $59+/-21 \mathrm{~min}$, respectively. There was one in-hospital death (3.3\%), and three deaths occurred within 12 months of follow up (one death was valve-related, and two deaths were independent of the valve implantation). The patients underwent to clinical and echocardiographic follow-up at discharge, 1, 3, 6 and 12 months after implant and then annually A total of 28 patients was assessed at one month post-implantation, and 23 after 12 months. No migration or dislodgement of the valve had occurred, but there were two mild paravalvular leakages and two mild intravalvular insufficiencies. The preliminary results of the trial confirmed the safety and efficacy of the Perceval $\mathrm{S}$ sutureless aortic valve. In this highrisk subset of patients, shortening the aortic cross-clamp and ECC times may help to reduce mortality and morbidity $[\underline{51}, \underline{52}, \underline{53}]$.

Based on the Pilot results, Sorin Biomedica Cardio S.r.l. designed the "PERCEVAL Pivotal Trial - V10801" aimed at confirming the safety and performance results of the first trial in a larger patient population and obtaining the CE mark with limited indication. In particular, the valve size range comprised 21,23 and $25 \mathrm{~mm}$ sizes and the target patient population was the one at high risk for surgical procedure of the first study (e.g. subjects older than 75 years, with NYHA class III and IV, Logistic EuroSCORE $>5 \%$, without aortic dilatation). In the Pivotal trial 150 patients were enrolled in 9 European Investigational Centers between January 2009 and January 2010. The primary endpoint was the evaluation of the safety and the performance (in terms of improvement of clinical status and hemodynamic performance) of the Perceval $S$ prosthesis at 3-6 months after implant. The secondary endpoints were the assessment of mortality and morbidity rates and of the performance at discharge (or 30 days if the patient is still hospitalized) and 12 months after implant.

Folliguet reported recently the results of a series of 208 high-risk patients operated in 2 European Centers [51]. Median follow up was 10 \pm 20 months and the total accumulated followup was 156 patient-years. Mean cross-clamp time and extracorporeal circulation time were 33 \pm 14 minutes and $54 \pm 24$ minutes respectively, including 45 patients who underwent surgery through ministernotomy. Concomitant coronary bypass was done in 48 patients. Mean preoperative and postoperative gradients were $48.6 \pm 18.6 \mathrm{~mm} \mathrm{Hg}$ and $10.4 \pm 4.3 \mathrm{~mm} \mathrm{Hg}$, respectively, and preoperative and postoperative mean effective orifice areas were $0.7 \pm 0.2$ and $1.4 \pm 0.4 \mathrm{~cm} 2$. Survival at 12 months was $87.1 \%$, success of implantation was $95 \%$, and freedom from reoperation was $96 \%$. In hospital mortality was $2.4 \%$. During follow-up, 9 patients (4\%) required reoperation for paravalvular regurgitation; 7 early and 2 late reoperations.

The authors concluded that Perceval sutureless is a safe bioprosthesis that can easily be implanted, including though a minimally invasive technique. Mid-term hemodynamics are very satisfying with significant clinical improvement.

\section{TECHNIQUE OF IMPLANTATION}

The procedure is performed through median sternotomy and usual exposure of the cardiac structures or through upper right ministernotomy. The aorta is cannulated as high as 
possible to allow a transverse aortotomy approximatively 3 to $3.5 \mathrm{~cm}$ above the expected level of the aortic anulus. Excision of the leaflets is performed in a standard fashion as the removal of irregular protruding anular calcifications. Basically there is no need to decalcify the annulus itself. Three guiding sutures are placed below the aortic annulus at the nadir of each sinus. Sizing of the annulus is performed with dedicated universal sizers (in the commercial phase they will be named as S-M-L$\mathrm{XL})$. The device is prepared on a side table by collapsing it (not crimping), and is mounted on dedicated delivery device. Guiding sutures are passed within the loops present on the external aspect of the inflow ring and the device can be now parachuted into the root. The guiding sutures assure correct alignment and prevent too low positioning into the LVOT. Correct intraanular positioning is checked before final release and is facilitated due to optimal visualization and low profile of the delivery device. The inflow and the outflow are released sequentially, the guiding sutures are removed. Final sealing is assured by dedicated balloon-dilation at 4 atmospheres for 30" under direct vision. Finally the aortotomy is closed as per routine.
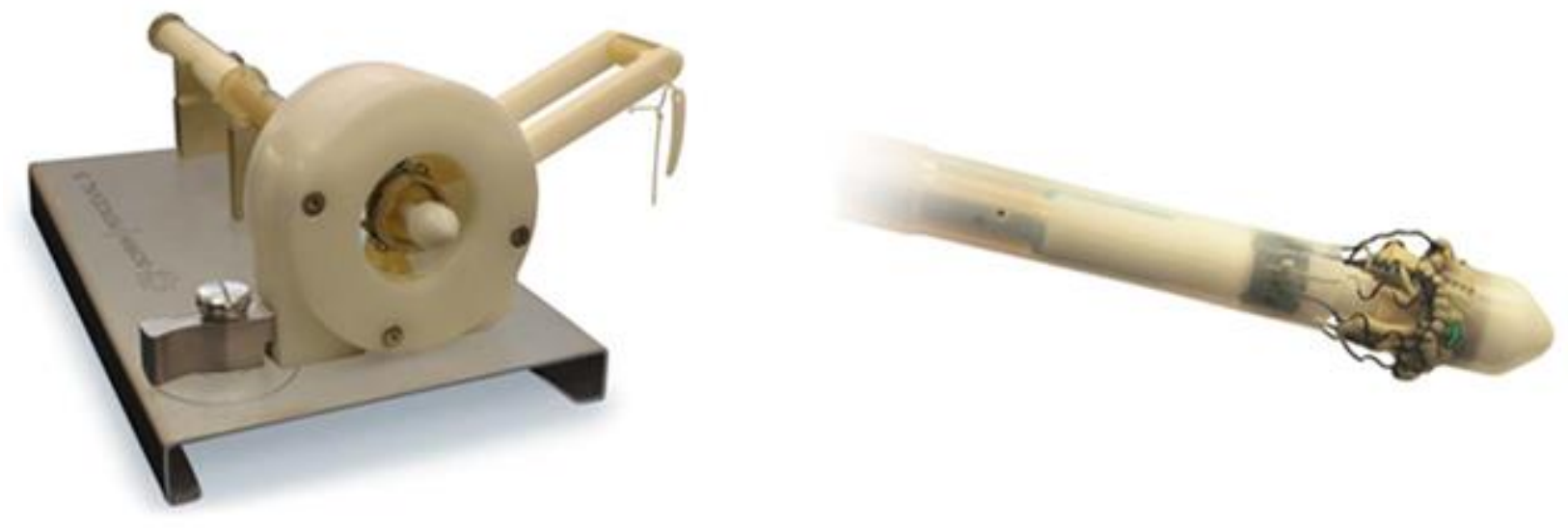

Figure 12. Valve to be collapsed (left) and ready for implantation (right)
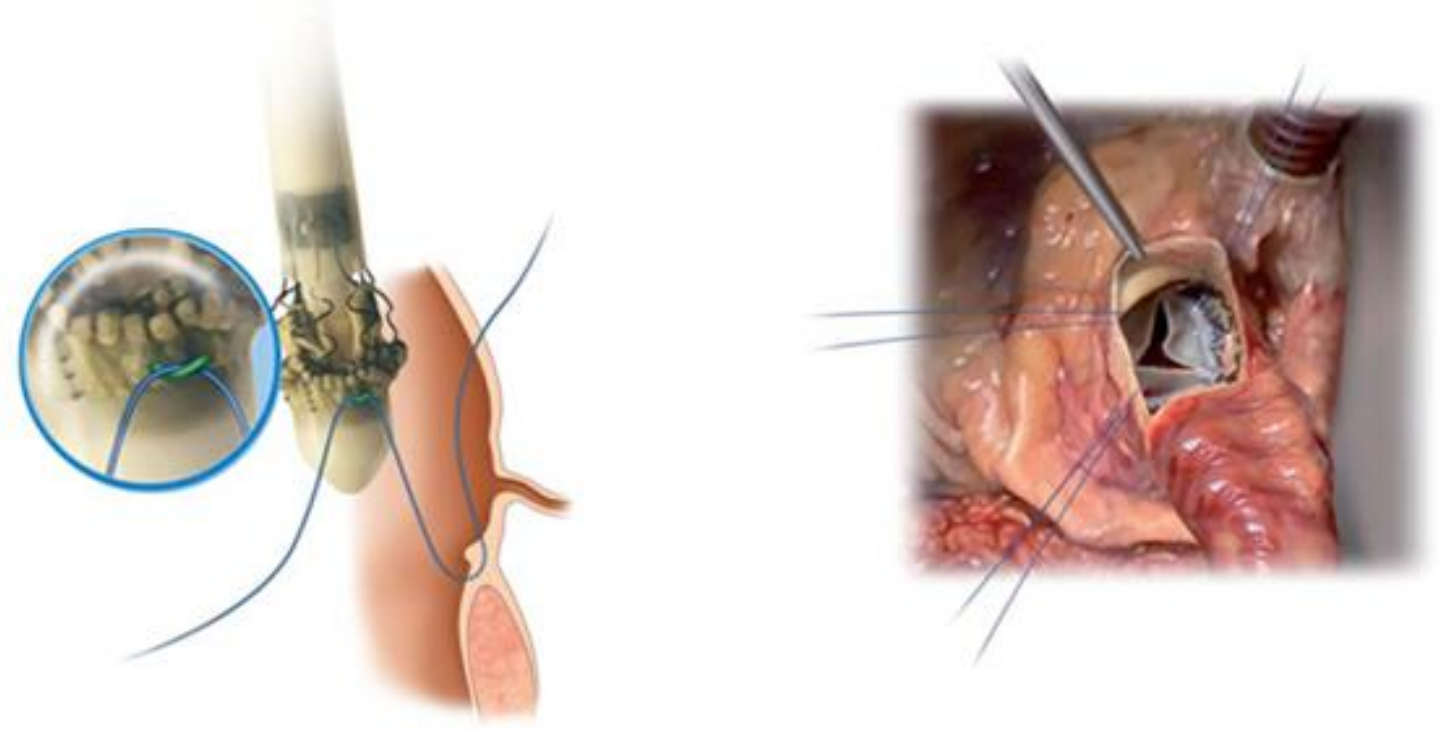

Figure 13. The guiding stitches are passed through the corresponding loops present at the external aspect of the inflow ring (left). The valve has been parachuted into position (right). 


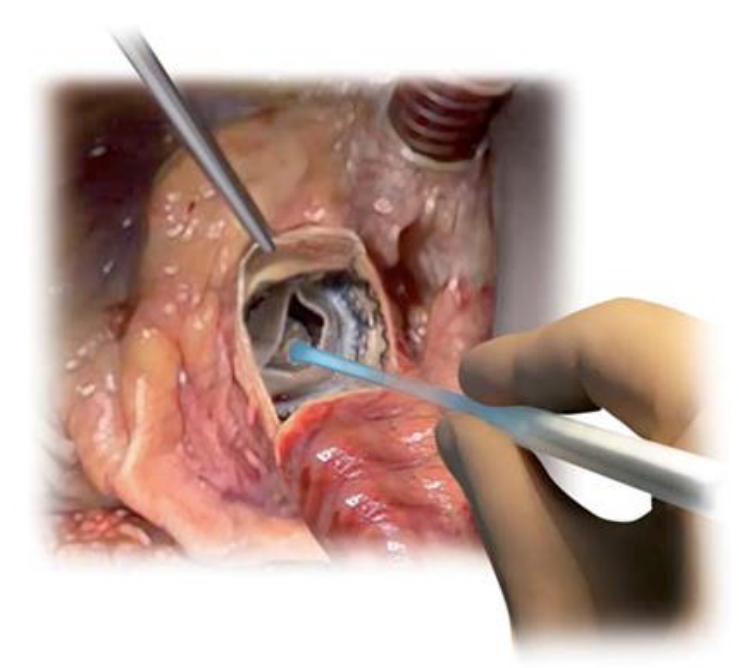

Figure 14. Final step of the implantation: dilatation of the Perceval S valve into the aortic annulus.

\section{CURRENT STUDY}

On the basis of the Pilot results and preliminary outcomes of the Pivotal study, Sorin Biomedica Cardio S.r.l. planned the CAVALIER study designed to evaluate the safety and effectiveness of the Perceval $S$ valve with extended indications in terms of age ( $\geq 65$ years) and valve sizes (21-23-25). A minimum of 300 patients will have been enrolled and followed to a minimum of 1 year post-implant. As necessary, additional patients will be implanted and followed until the requirement of 800 valveyears of experience is achieved. The primary endpoint is the evaluation of the safety and effectiveness (in terms of improvement of clinical status and hemodynamic performance) of the Perceval $\mathrm{S}$ valve at 12 months after implant, while the secondary endpoints are the assessment of mortality and morbidity rates and of the effectiveness at discharge and at 3-6 months follow-up. The study started in February 2010 and at present the patients enrolment is still currently ongoing in 25 European Investigational Centers with 317 patients implanted.

According to the larger present experience in more centers than in the pilot study, the Perceval $S$ sutureless bioprosthesis is userfriendly and has a low profile device. Implantation can be performed easily after a short learning curve, even in small and/or calcified aortic roots. The procedure is facilitated because sutures are not required and the deployment starts from a completely collapsed prosthesis. In the present experience, the Perceval S system allowed for at least $50 \%$ reduction of aortic cross-clamp time, the shortest clamping time being around 15 to 18 minutes. This may have a positive impact on post-operative outcomes, especially if preoperative conditions are border-line (severe COPD / renal dysfunction), or in older age patients as well as in situations where concomitant procedures are needed (CABG, AFib ablation, PFO closure and others). Clinical proven durability at 4 years, since more than 500 pts already operated upon since 2007, and predicate device and lab tests show promising long-term durability.

\section{EXPERIMENTAL TRANSAPICAL IMPLANTATION OF THE PERCEVAL $S$ VALVE}

Transapical aortic valve implantation offers the possibility to deploy a prosthetic aortic valve mounted on a stent in accordance with these principles. The antegrade approach to the aortic valve through the left ventricular apex is particularly helpful when there is significant occlusive disease and/or calcification of the aorto-iliac bifurcation, and in case of heavy calcification of the ascending aorta (porcelain aorta) the transapical valve insertion may diminish the risk of stroke.

The main currently available transapical device is the Edwards Sapien valve, while the CoreValve prosthesis has been used occasionally for transapical valve implantation [55, $\underline{56}$. The procedure relies on an ability to anchor the valve within the native aortic valve calcification, using radial force to prevent retrograde slippage or distal embolization. The most dreaded complication of transcatheter implantation of an aortic valve following balloon dilation relates to the embolization of calcific debris from the native aortic valve.

Off-pump transapical aortic valve implantation was performed through a left minithoracotomy using a bovine pericardial valve mounted on a self-expandable nitinol stent of size $21 \mathrm{~mm}$ and $23 \mathrm{~mm}$ in 11 pigs (average weight $60 \mathrm{~kg}$ ). The collapsed valve was introduced through the left ventricular apex 
using a flexible and steerable delivery sheath, using a three-step technique. Biplane fluoroscopy and transesophageal echocardiography were simultaneously used for guidance. Successful adjustment of alignment along three axes prior to deployment of the valve was accomplished in each animal. Deployments were performed during a period of rapid pacing.

All valves were successfully deployed and functioned normally following transapical removal of the delivery system. Paravalvular leak was documented in one case $(9.1 \%)$ due to prosthetic misalignment. There was no evidence of valve migration. Correct anatomic seating was confirmed during post-procedure necropsy. Successful transapical implantation of this novel self-expandable bovine pericardial valve was accomplished in 11 animals, without cardiopulmonary bypass. A flexible, steerable delivery system with a three-step release mechanism allowed precise positioning of the valve with a low rate of paravalvular leakage, and excellent device stability.

The implantation of an expandable aortic valve prosthesis via the left ventricular apex currently relies upon an ability to anchor the prosthesis within the native leaflet calcium. Whilst successful in the majority of patients, this relatively new procedure unfortunately leaves the diseased native valve in place, exposing the patient to the potential risk for distal embolization of either calcific debris or the prosthesis itself [57]. Furthermore, the longterm impact of residual paravalvular leakage due to deployment within an irregular annular circumference is unknown. The Perceval valve addresses these potential limitations, allowing deployment of the prosthesis within a circular orifice, and optimal adaptation to the native aortic sinus dimensions. The three-step deployment mechanism allows a controlled release process of the valve, guided both by aortic root angiography and TEE. The initial results of transapical deployment in a pig model .revealed that the technique was safe and reproducible.

The ideal design for the transapical catheter delivery of a biological valve should aim at removal of the native valve, followed by sutureless prosthetic replacement. This strategy would be close to the 'gold standard' represented by the conventional prosthetic valve replacement that has been performed routinely for the past four decades. Strategies for the transapical resection of native aortic valve tissue have been examined and reported [58-61]. For example, a sophisticated method of in-situ transluminal resection of aortic valve leaflets using a YAG laser within an aortic valve isolation chamber has been developed. In a retrograde cadaver model, it was shown that each cusp could be resected with an average time of 6 minutes. The most recent report from this group compared the antegrade and retrograde approaches, and demonstrated that 'fewer severe lesions' occurred in the aorta when using a transapical antegrade approach compared to the transluminal retrograde strategy [62]. Salizzoni and colleagues, from the University of Pittsburgh, have recently shown that a percutaneous removal of the aortic valve is possible off-pump in animals [63]. The new design of the Perceval valve, combined with the pericardial inflow skirt, are most likely responsible for the impressive freedom from paravalvular leakage reported in humans to date. This contrasts with all other clinically available transcatheter valve procedures using various prostheses [64]. Furthermore, the ability to crimp the device for transapical or transfemoral delivery makes it very attractive [65]. While the first-generation Cribier-Edwards prosthesis utilized equine pericardium, the current version CoreValve leaflets are composed of porcine pericardium, the late durability of which has not been evaluated in humans [66]. Other valve prostheses use bovine pericardium, which has been employed in stented valves for over two decades, and an initial clinical experience with the Ventor Embracer (Ventor Technogies, Netanya, Israel) was recently published [67]. This is a bovine pericardial valve with a selfexpanding nitinol stent and three support arms that are lodged in the aortic sinuses, so as to allow self-centering and both axial and radial forces for stabilization. The Perceval valve is based on the bovine pericardial Sorin bioprosthesis which has been used clinically since 1985 , and has a well-documented performance $[\underline{68}, \underline{69}]$. 


\section{THE INTUITY SUTURELESS VALVE FROM EDWARDS}

The Edwards Intuity valve system leverages a proven valve platform and features an innovative balloon-expandable frame for rapid deployment. The bovine pericardial tissue used for construction of this valve is treated by Thermafix process which is similar to that already used for the stented Permount valves from the same company. The Intuity sutureless valve includes a broad polyester sealing cloth to be expanded at the level and slightly below the native aortic valve anulus which covers the balloon expandable stainless steel frame (Figures $\underline{15}$ and $\underline{16}$ ).

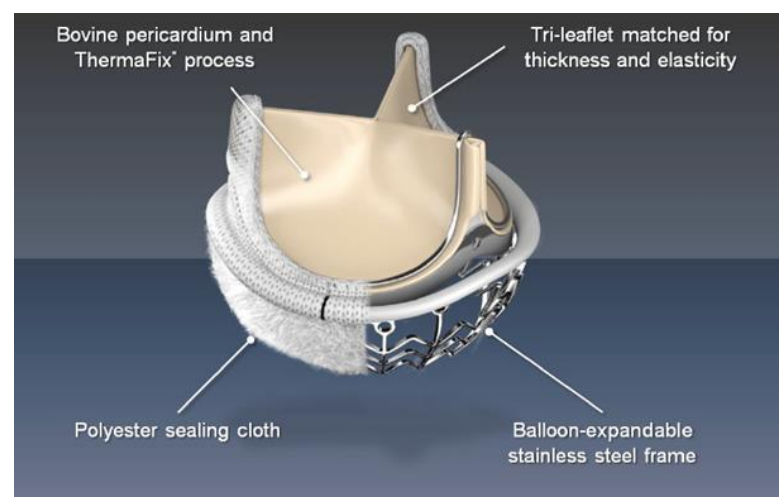

Figure 15. The Intuity sutureless valve (courtesy from Edwards)

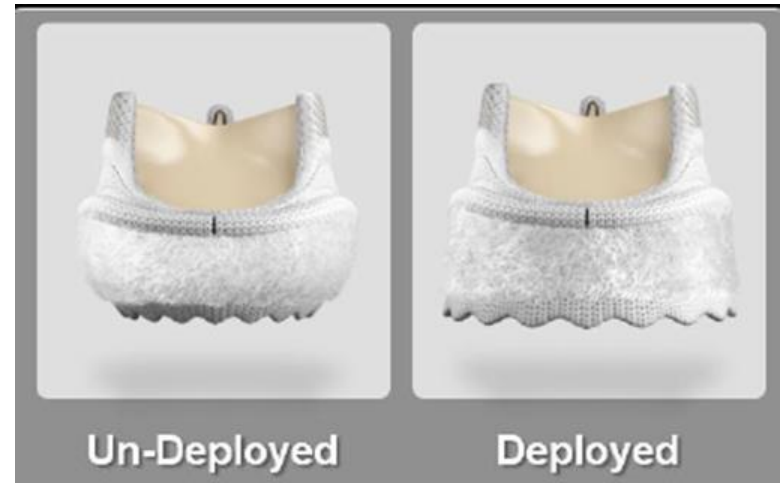

Figure 16. The large polyester cuff of the Intuity valve ensures optimal sealing at the level of the anulus and just below (courtesy from Edwards)

In the prospective, single-arm TRITON trial, six European centres treated 152 consecutive patients in need of surgical aortic valve replacement [70]. Procedural success was $97.3 \%$. Surgeons performed 86 isolated aortic valve replacement procedures, with about half of these cases using small-incision approaches. Mean EOA and gradients were $1.7 \pm 0.1 \mathrm{~cm} 2$ and
$8.4 \pm 0.7 \mathrm{~mm} \mathrm{Hg}$ at three months and remained unchanged at one-year follow-up. All data were adjudicated by a clinical event committee and were Echocardiography Core Lab reviewed.The immediate incidence of paravalvular leaks was low. Valve-related mortality rates were low in the mid-term; survival in this group of patients was $98.6 \%$ at 30 days and, at one year, the Kaplan-Meier curve demonstrated $94 \%$ freedom from death.

The data also demonstrated shortened procedures, as characterised by acceptably short cross-clamp times and times spent on cardiopulmonary bypass. For isolated aortic valve replacement cases, mean aortic crossclamp times were reduced by $48 \%$, and mean bypass times by $39 \%$, compared to times noted in the Society of Thoracic Surgeons' Adult Cardiac Database.

The study gave the authors confidence in the opportunity to use this system with lessinvasive surgical approaches. The overall performance of the Edwards Intuity valve system is promising, due to the early excellent haemodynamic results and the design inspired by the proven platform of Edwards' family of surgical valves. The Edwards Intuity valve system received CE mark in Europe in February 2012.

\section{STUDY SUMMARY}

Although attractive, a strategy of valve excision before prosthesis implantation still relies on an ability to resect the native aortic valve, and to implant a new prosthesis while maintaining hemodynamic stability. The optimization of catheter-based resection techniques will be necessary before this can be achieved. However, in the less-frequent conditions leading to aortic insufficiency with thin pliable leaflets and a preserved aortic root anatomy, (e.g. endocarditis, perforation), valve resection would not be necessary. Finally, the ability to place the aortic root sinus-conforming stent against the aortic wall relies on the absence of aortic root or ascending aortic dilatation. In conclusion, transapical implantation of the Perceval self-expanding bovine pericardial valve without $C P B$ is technically feasible and safe. A flexible, steerable delivery system with a three-step release mechanism allows for a precise positioning of 
the valve, with a very low rate of paravalvular leakage and excellent device stability. The preliminary results of this trial will hopefully reenergize the search for strategies to perform native valve resection, and thereby facilitate the clinical introduction of truly minimally invasive transapical aortic valve replacement.

\section{CONCLUSIONS}

Presently three different types of sutureless valve are available on the market with distinct designs and different deployment techniques. The definitive clinical use is difficult to predict but these valves may become substitutes for all conventional stented and stentless biological valves; in addition these

\section{REFERENCES}

[1] Soler-Soler J, Galve E. Worldwide perspective of valve disease. Heart. 2000; 83 :721-5.

[2] lung B, Baron G, Butchart EG, Delahaye F, Gohlke-Barwolf C, Levang OW, Tornos P, Vanoverschelde JL, Vermeer F, Boersma $E$, Ravaud P, Vahanian A. A prospective survey of patients with valvular heart disease in Europe: the Euro Heart Survey on valvular heart disease. Eur Heart J. 2003; 24: 1231-43.

[3] Stewart BF, Siscovick D, Lind BK, Gardin JM, Gottdiener JS, Smith VE, Kitzman DW, Otto $\mathrm{CM}$. Clinical factors associated with calcific aortic valve disease. Cardiovascular Health Study. J Am Coll Cardiol. 1997; 29: 630-4.

[4] Otto CM, Lind BK, Kitzman DW, Gersh BJ, Siscovick DS. Association of aortic-valve sclerosis with cardiovascular mortality and morbidity in the elderly. N Engl J Med. 1999; 341: 142-7.

[5] Otto CM, Burwash IG, Legget ME, Munt BI, Fujioka M, Healy NL, Kraft CD, Miyake-Hull CY, Schwaegler RG. Prospective study of asymptomatic valvular aortic stenosis. Clinical, echocardiographic, and exercise predictors of outcome. Circulation. 1997; 95: 2262-70.

[6] Rosenhek R, Binder T, Porenta G, Lang I, Christ G, Schemper M, Maurer G, Baumgartner $\mathrm{H}$. Predictors of outcome in severe, asymptomatic aortic stenosis. $N$ Engl J Med. 2000; 343: 611-7.

[7] Pellikka PA, Sarano ME, Nishimura RA, Malouf JF, Bailey KR, Scott CG, Barnes ME, Tajik AJ. Outcome of 622 adults with asymptomatic, hemodynamically significant aortic stenosis during prolonged follow-up. Circulation. 2005; valves have a potential for breakthrough of minimal access surgery since they may facilitate valve replacement through such approaches. Finally the more the use and deployment of sutureless valves will be simplified, the more a broad surgical community will adopt this new technology. Today it remains difficult to predict which patients may be the best candidates for sutureless valve implantation and in which ones a maximal benefit would be observed.

\section{CONFLICT OF INTEREST}

Thierry Carrel, Lars Englberger and Mario Stalderv received speaker honoraria from ATSMedtronic and Sorin.

\section{1: 3290-5.}

[8] STS national database: STS U.S. cardiac surgery database: 1997 Aortic valve replacement patients: preoperative risk variables. Chicago, Society of Thoracic Surgeons; 2000. Accessed 10 May 2006. http:// www.ctsnet.org/doc/3031

[9] Bridgewater B, Keogh B, Kinsman R, Walton P. The Society for Cardiothoracic Surgery in Great Britain \& Ireland, 6th National Adult Cardiac Surgical Database Report; Demonstrating quality, 2008. Dendrite Clinical Systems Ltd, Henley-on-Thames, United Kingdom. ISBN 1903968-23-2, published July 2009

[10] Kvidal P, Bergström R, Hörte LG, Ståhle E. Observed and relative survival after aortic valve replacement. J Am Coll Cardiol. 2000; 35: 747-56.

[11] Smith N, McAnulty JH, Rahimtoola SH. Severe aortic stenosis with impaired left ventricular function and clinical heart failure: results of valve replacement. Circulation. 1978; 58: 25564.

[12] Hesslein PS, McNamara DG, Morriss MJ, Hallman GL, Cooley DA. Severe aortic stenosis in patients 60 years of age or older: left ventricular function and 10 -year survival after valve replacement. Circulation. 1981; 64: 1848.

[13] Schwarz F, Baumann P, Manthey J, Hoffmann M, Schuler G, Mehmel HC, Schmitz W, Kübler $W$. The effect of aortic valve replacement on survival. Circulation. 1982; 66: 1105-10.

[14] Pai RG, Kapoor N, Bansal RC, Varadarajan P. Malignant natural history of asymptomatic 
severe aortic stenosis: benefit of aortic valve replacement. Ann Thorac Surg. 2006; 82: 2116-22.

[15] Mihaljevic T, Nowicki ER, Rajeswaran J, Blackstone EH, Lagazzi L, Thomas J, Lytle BW, Cosgrove DM. Survival after valve replacement for aortic stenosis: implications for decision making. J Thorac Cardiovasc Surg. 2008; 135: 1270-9.

[16] Brown ML, Pellikka PA, Schaff HV, Scott CG, Mullany CJ, Sundt TM, Dearani JA, Daly RC, Orszulak TA. The benefits of early valve replacement in asymptomatic patients with severe stenosis. J Thorac Cardiovasc Surg. 2008; 135: 308-15.

[17] Vahanian A, Alfieri O, Andreotti F, Antunes MJ, Barón-Esquivias $\mathrm{G}$, Baumgartner $\mathrm{H}$, Borger MA, Carrel TP, De Bonis M, Evangelista A, Falk V, lung $B$, Lancellotti $P$, Pierard $L$, Price $S$, Schäfers HJ, Schuler G, Stepinska J, Swedberg K, Takkenberg J, Von Oppell UO, Windecker S, Zamorano JL, Zembala M; ESC Committee for Practice Guidelines (CPG), Bax JJ, Baumgartner $\mathrm{H}$, Ceconi C, Dean V, Deaton C, Fagard R, Funck-Brentano C, Hasdai D, Hoes A, Kirchhof $P$, Knuuti J, Kolh $P$, McDonagh $T$, Moulin $C$, Popescu BA, Reiner Z, Sechtem U, Sirnes PA, Tendera M, Torbicki A, Vahanian A, Windecker S; Document Reviewers:, Popescu BA, Von Segesser L, Badano LP, Bunc M, Claeys MJ, Drinkovic N, Filippatos G, Habib G, Kappetein $A P$, Kassab R, Lip GY, Moat N, Nickenig G, Otto CM, Pepper J, Piazza N, Pieper PG, Rosenhek R, Shuka N, Schwammenthal E, Schwitter J, Mas PT, Trindade PT, Walther T. Guidelines on the management of valvular heart disease (version 2012): The Joint Task Force on the management of Valvular Heart Disease of the European Society of Cardiology (ESC) and the European Association for Cardiothoracic Surgery (EACTS). Eur Heart J. 2012; 33: 245196.

[18] Bakhtiary F, Schiemann M, Dzemali O, Wittlinger $T$, Doss $M$, Ackermann $H$, Moritz A, Kleine P. Stentless bioprostheses improve coronary blood flow more than stented prostheses after valve replacement for aortic stenosis. J Thorac Cardiovasc Surg. 2006; 131: 883-8.

[19] Leon MB, Smith CR, Mack M, Miller DC, Moses JW, Svensson LG, Tuzcu EM, Webb JG, Fontana GP, Makkar RR, Brown DL, Block PC, Guyton $R A$, Pichard $A D$, Bavaria JE, Herrmann HC, Douglas PS, Petersen JL, Akin JJ, Anderson WN, Wang $D$, Pocock S; PARTNER Trial Investigators. Transcatheter aortic-valve implantation for aortic stenosis in patients who cannot undergo surgery. N Engl J Med. 2010; 363: 1597-607.

[20] Thomas M, Schymik G, Walther T, Himbert D, Lefèvre $T$, Treede $H$, Eggebrecht $H$, Rubino $P$, Michev I, Lange R, Anderson WN, Wendler O; on behalf of the SOURCE Investigators. ThirtyDay results of the SAPIEN Aortic Bioprothesis European Outcome (SOURCE) Registry: A European Registry of Transcatheter Aortic Valve Implantation Using the Edwards SAPIEN Valve. Circulation. 2010; 122: 62-9.

[21] Piazza N, Grube E, Gerckens U, den Heijer P, Linke A, Luha O, Ramondo A, Ussia G, Wenaweser $\mathrm{P}$, Windecker S, Laborde JC, de Jaegere $\mathrm{P}$, Serruys PW. Procedural and 30-day outcomes following transcatheter aortic valve implantation using the third generation (18 Fr) CoreValve revalving system: results from the multicentre, expanded evaluation registry 1year following CE mark approval. Eurolntervention. 2008; 2: 242-9.

[22] Zahn R, Gerckens U, Grube E, Linke A, Sievert $H$, Eggebrecht $H$, Hambrecht $R$, Sack $S$, Hauptmann KE, Richardt G, Figulla HR, Senges $\mathrm{J}$; on behalf of the German Transcatheter Aortic Valve Interventions-Registry Investigators. Transcatheter aortic valve implantation: first results from a multi-centre real-world registry. Eur Heart J. 2010; 32: 198204.

[23] Walther T, Kasimir MT, Doss M, Schuler G, Simon $\mathrm{P}$, Schächinger $\mathrm{V}$, Mohr FW, WimmerGreinecker G. One-year interim follow-up results of the TRAVERCE trial: the initial feasibility study for trans-apical aortic-valve implantation. Eur J Cardiothorac Surg. 2010; 9: 532-7.

[24] Petronio AS, De Carlo M, Bedogni F, Marzocchi A, Klugmann $S$, Maisano $F$, Ramondo A, Ussia GP, Ettori F, Poli A, Brambilla N, Saia F, De Marco F, Colombo A. Safety and efficacy of the subclavian approach for transcatheter aortic valve implantation with the CoreValve revalving system. Circ Cardiovasc Interv. 2010; 3: 359-66.

[25] Lefèvre $T$, Kappetein AP, Wolner $E$, Nataf $P$, Thomas $M$, Schächinger $V$, De Bruyne $B$, Eltchaninoff $H$, Thielmann $M$, Himbert $D$, Romano M, Serruys P, Wimmer-Greinecker G; on behalf of the PARTNER EU Investigator Group. One year follow-up of the multi-centre European PARTNER transcatheter heart valve study. Eur Heart J. 2010; 32: 148-57.

[26] Gurvitch R, Wood DA, Tay EL, Leipsic J, Ye J, Lichtenstein SV, Thompson CR, Carere RG, Wijesinghe N, Nietlispach F, Boone RH, Lauck S, Cheung A, Webb JG. Transcatheter aortic 
valve implantation: durability of clinical and hemodynamic outcomes beyond 3 years in a large patient cohort. Circulation. 2010; 122: 1319-27.

[27] Kalavrouziotis D, Li D, Buth KJ, Légaré JF. The European System for Cardiac Operative Risk Evaluation (EuroSCORE) is not appropriate for withholding surgery in high-risk patients with aortic stenosis: a retrospective cohort study. J Cardiothorac Surg. 2009; 4: 32.

[28] Vasa-Nicotera M, Sinning JM, Chin D, Lim TK, Spyt $T$, Jilaihawi $H$, Grube $E$, Werner $N$, Nickenig G, Kovac J. Impact of paravalvular leakage on outcome in patients after transcatheter aortic valve implantation. JACC Cardiovasc Interv. 2012; 8: 858-65.

[29] Rosenhek R, Zilberszac R, Schemper M, Czerny $M$, Mundigler G, Graf S, Bergler-Klein J, Grimm M, Gabriel H, Maurer G. Natural history of very severe aortic stenosis. Circulation. 2010; 121: 151-6.

[30] Brown ML, Pellikka PA, Schaff HV, Scott CG, Mullany CJ, Sundt TM, Dearani JA, Daly RC, Orszulak TA. The benefits of early valve replacement in asymptomatic patients with severe aortic stenosis. J Thorac Cardiovasc Surg. 2008; 135: 308-15.

[31] Kang DH, Park SJ, Rim JH, Yun SC, Kim DH, Song JM, Choo SJ, Park SW, Song JK, Lee JW, Park PW. Early surgery versus conventional treatment in asymptomatic very severe aortic stenosis. Circulation. 2010; 121: 1502-9.

[32] Vahanian A, Baumgartner $H$, Bax J, Butchart $E$, Dion R, Filippatos G, Flachskampf $F$, Hall R, lung $B$, Kasprzak J, Nataf $P$, Tornos $P$, Torracca $L$, Wenink A; Task Force on the Management of Valvular Hearth Disease of the European Society of Cardiology; ESC Committee for Practice Guidelines. Guidelines on the management of valvular heart disease: The Task Force on the Management of Valvular Heart Disease of the European Society of Cardiology. Eur Heart J. 2007; 28: 230-68.

[33] Hufnagel CA, Harvey WP, Rabil PJ, McDermott TF. Surgical correction of aortic insufficiency. Surgery. 1954; 35: 673-83.

[34] Starr A, Edwards ML. Mitral replacement: clinical experience with a ball-valve prosthesis. Ann Surg. 1961; 154: 726-40.

[35] Chaikof EL. The development of prosthetic heart valves: lessons in form and function. $N$ Engl J Med. 2007; 357: 1368-71.

[36] Hammermeister K, Sethi GK, Henderson WG, Grover FL, Oprian C, Rahimtoola SH. Outcomes 15 years after valve replacement with a mechanical versus a bioprosthetic valve: final report of the Veterans Affairs randomized trial. J Am Coll Cardiol. 2000; 36: 1152-8.

[37] Oxenham $H$, Bloomfield P, Wheatley DJ, Lee RJ, Cunningham J, Prescott RJ, Miller HC. Twenty year comparison of a Bjork-Shiley mechanical heart valve with porcine bioprostheses. Heart. 2003; 89: 715-21.

[38] Stassano P, Di Tommaso L, Monaco M, lorio F, Pepino $P$, Spampinato $N$, Vosa C. Aortic valve replacement: a prospective randomized evaluation of mechanical versus biological valves in patients ages 55 to 70 years. $J \mathrm{Am}$ Coll Cardiol. 2009; 54: 1862-8.

[39] Grunkemeier GL, Li HH, Naftel DC, Starr A, Rahimtoola $\mathrm{SH}$. Long-term performance of heart valve prostheses. Curr Probl Cardiol. 2000; 25: 73-154.

[40] Butchart EG, Gohlke-Bärwolf C, Antunes MJ, Tornos P, De Caterina R, Cormier B, Prendergast $B$, lung $B$, Bjornstad $H$, Leport $C$, Hall RJ, Vahanian A; Working Groups on Valvular Heart Disease, Thrombosis, and Cardiac Rehabilitation and Exercise Physiology, European Society of Cardiology. Recommendations for the management of patients after heart valve surgery. Eur Heart J. 2005; 26: 2463-71.

[41] Sun JC, Davidson MJ, Lamy A, Eikelboom JW. Antithrombotic management of patients with prosthetic heart valves: current evidence and future trends. Lancet. 2009; 374: 565-76.

[42] Montori VM, Ting HH. Sharing decision making about cardiac surgery: improving the quality of the decision to undergo or forego surgery. Circ Cardiovasc Qual Outcomes. 2009; 2: 519-21.

[43] Herzog CA, Ma JZ, Collins AJ. Long-term survival of dialysis patients in the United States with prosthetic heart valves: should ACC/AHA practice guidelines on valve selection be modified? Circulation. 2002; 105: 1336-41.

[44] Heneghan C, Alonso-Coello P, Garcia-Alamino $J M$, Perera R, Meats E, Glasziou P. Selfmonitoring of oral anticoagulation: a systematic review and meta-analysis. Lancet. 2006; 367: 404-11.

[45] Magovern GJ, Cromie HW. Sutureless prosthetic heart valves. J Thorac Cardiovasc Surg. 1963; 46: 726-36.

[46] Pillai R, Soon JL, Martens S, Doss M, Carrel T, Sadowski J, Eckstein F, Bartus K, Kapelak B. Aortic cusp replacement using the ATS $3 f$ stentless pericardial valve. Innovations. 2011, in press.

[47] Cox JL, Ad N, Myers K, Gharib M, Quijano RC. Tubular heart valves: A new tissue prosthesis design preclinical evaluation of the $3 \mathrm{~F}$ Aortic Bioprosthesis. J Thorac Cardiovasc Surg. 2005;

Page 19 of 21

(Page number not for citation purposes) 
130: 520-27.

[48] Cox JL. The ATS 3f Aortic Bioprosthesis. In: Yankah CA, Weng Y, Hetzer R, eds. Aortic root surgery: The biological solution. Berlin: Springer-Verlag; 2010: 386-95.

[49] Doss M, Martens S, Wood JP, Miskovic A, Christodoulou T, Wimmer-Greinecker G, Moritz A. Aortic leaflet replacement with the new $3 F$ stentless aortic bioprosthesis. Ann Thorac Surg. 2005; 79: 682-5.

[50] Aymard T, Eckstein F, Englberger L, Stalder M, Kadner A, Carrel T. The Sorin Freedom SoloTM Stentless Aortic Valve: Technique of Implantation and Operative Results in 109 Patients. J Thorac Cardiovasc Surg. 2010; 139: 775-7.

[51] Folliguet T, Laborde F, Zannis K, Ghorayeb G, Haverich A, Schresta M. Sutureless Perceval aortic valve replacement: reuslts of two European Centers. Ann Thorac Surg. 2012; 93:1483-8.

[52] Shresta M, Khaladj N, Bara C Höffler K, Hagl C, Haverich A. A staged approach towards interventional aortic valve implantation with a sutureless valve: initial human implants. Thorac Cardiovasc Surg. 2008; 56: 398-400.

[53] Shrestha M, Folliguet T, Meuris B, Dibie A, Bara C, Herregods MC, Khaladj N, Hagl C, Flameng W, Laborde F, Haverich A. Sutureless Perceval $S$ aortic valve replacement: a multicenter, prospective study. I Heart Valve Dis. 2009; 18: 698-702.

[54] Stalder M, Suri RM, Kraehenbuehl ES, Hellige G, Wenaweser P, Zobrist C, Schaff HV, Carrel TP. Transapical implantatiob if a novel selfexpandng sutureless aortic valve prosthesis. J Heart Valve Dis. 2010; 19: 182-7.

[55] Lange R, Schreiber C, Götz W, Hettich I, Will A, Libera P, Laborde JC, Bauernschmitt R. First successful transapical aortic valve implantation with the Corevalve Revalving system: A case report. Heart Surg Forum. 2007; 10: E478-9.

[56] Bleiziffer S, Ruge H, Mazzitelli D, Schreiber C, Hutter A, Laborde JC, Bauernschmitt R, Lange R. Results of percutaneous and transapical transcatheter aortic valve implantation performed by a surgical team. Eur J Cardiothorac Surg. 2009; 35: 615-20.

[57] Ranasinghe I, Yiannikas J, Brieger D. Acute left main occlusion secondary to embolisation from an aortic valve prosthesis: successful treatment with embolectomy and percutaneous coronary intervention. Int J Cardiol. 2009; 149: e110-2.

[58] Quaden R, Attmann T, Schünke M, TheisenKunde D, Cremer J, Lutter G. Percutaneous aortic valve replacement: Endovascular resection of human aortic valves in situ. J Thorac Cardiovasc Surg. 2008; 135: 1081-6.

[59] Quaden R, Klaws GR, Theisen-Kunde D, Lutter G. Percutaneous aortic valve replacement: First endovascular resection of human aortic valves in situ. Eur J Cardiothorac Surg. 2007; 31: 305.

[60] Attmann T, Lutter G, Quaden R, Jahnke T, Rumberg K, Cremer J, Muller-Hulsbeck S. Percutaneous valve replacement: Significance of different delivery systems in vitro and in vivo. Cardiovasc Intervent Radiol. 2006; 29: 406-12.

[61] Quaden R, Attmann T, Boening A, Cremer J, Lutter G. Percutaneous aortic valve replacement: Resection before implantation. Eur J Cardiothorac Surg. 2005; 27: 836-40.

[62] Bombien RH, Appel M, Attmann T, Klaws GR, Schünke $M$, Hass $C$, Cremer J, Lutter $G$. Percutaneous aortic valve replacement: Gross anatomy and histological findings after transapical and endoluminal resection of human aortic valves in situ. Eur J Cardiothorac Surg. 2009; 36: 112-17.

[63] Salizzoni S, Bajona P, Zehr KJ, Anderson WD, Vandenberghe $S$, Speziali G. Transapical offpump removal of the native aortic valve: $A$ proof of concept animal study. J Thorac Cardiovasc Surg. 2009; 138: 468-73.

[64] Wendt $D$, Thielmann $M$, Buck $T$, Jánosi RA, Bossert T, Pizanis N, Kamler M, Jakob H. First clinical experience and 1-year follow-up with the sutureless 3F-Enable aortic valve prosthesis. Eur J Cardiothorac Surg. 2008; 33: 542-7.

[65] Neyt M, Vinck I, Gewillig M, Van Brabandt H. Percutaneous pulmonary and aortic valve insertion in Belgium: Going for conditional reimbursement or waiting for further evidence? Int J Technol Assess Health Care. 2009; 25: 281-9.

[66] Walther T, Chu MWA, Mohr FW. Transcatheter aortic valve implantation: Time to expand? Curr Opin Cardiol. 2008; 23: 111-6.

[67] Falk V, Schwammenthal EE, Kempfert J, Linke A, Schuler G, Mohr FW, Walther T. New anatomically oriented transapical aortic valve implantation. Ann Thorac Surg. 2009; 87: 9256.

[68] Seguin JR, Grandmougin D, Folliguet T, Warembourg $H$, Laborde F, Chaptal PA. Longterm results with the Sorin Pericarbon valve in the aortic position: A multicenter study. J Heart Valve Dis. 1998; 7: 278-82.

[69] D'Onofrio A, Auriemma S, Magagna P, Favaro A, Cannarella A, Piccin C, Bilotta M, Abbiate N,

Page $\mathbf{2 0}$ of $\mathbf{2 1}$

(Page number not for citation purposes) 
Lamascese N, Fabbri A. Aortic valve replacement with the Sorin Pericarbon Freedom stentless prosthesis: 7 years' experience in 130 patients. J Thorac Cardiovasc Surg. 2007; 134: 491-5.

[70] Kocher A, Laufer G, Haverich A, Schresta M, Walther T, Misfeld M, Kempfert J, Gillam L, Schmitz C, Wahlers T, Wippermann J, Mohr
FW, Roth M, Skwara A, Rahmanian P, Wiedermann D, Borger M. One-year outcomes of the Surgical Treatment of Aortic Stenosis With a Next Generation Surgical Aortic Valve (TRITON) trial: A prospective multicenter study of rapid-deployment aortic valve replacement with the EDWARDS INTUITY Valve System. J Thorac Cardiovasc Surg. 2013; 145: 110-6.
Publish with ROSS Science Publishers and every scientist can easily read your

Science Publishers work for free!
Your research papers will be:

- $\quad$ available for free to the entire scientific community

- peer reviewed and published immediately after acceptance

- cited in renowned open repositories upon indexation of the journal

- $\quad$ owned by yourself - author keeps the copyright 